Ophthalmologe $2021 \cdot 118: 119-120$ https://doi.org/10.1007/s00347-020-01299-9 Angenommen: 4. Dezember 2020 Online publiziert: 4. Januar 2021 ๑) Springer Medizin Verlag GmbH, ein Teil von Springer Nature 2020

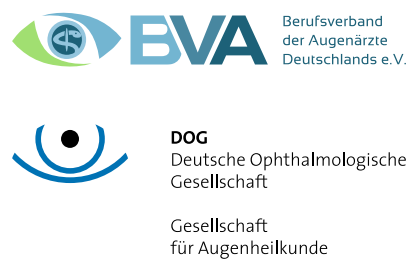

Diese Empfehlungen beschreiben das Vorgehen bei der Perimetrie (mit Halbkugelperimeter) während der SARS$\mathrm{CoV}-2$ („severe acute respiratory syndrome coronavirus 2")-Pandemie. Die Hygienemaßnahmen sollen sowohl SARSCoV-2-Infektionen bei Patienten und Personal vermeiden als auch die Verbreitung verhindern. Perimetrieuntersuchungen sollen nicht bei bestehender SARS-CoV-2-Infektion, nicht bei SARSCoV-2-Verdacht, bis eine SARS-CoV-2Infektion ausgeschlossen ist, und nur bei Patienten ohne auf SARS-CoV-2-Infektion weisende Symptome durchgeführt werden. Die Vorgaben der Behörden sind zu beachten.

Bei Symptomfreiheit ist trotzdem eine Infektion mit Übertragung einer SARSCoV-2-Infektion möglich, da ein Teil der SARS-CoV-2-Fälle asymptomatisch verläuft und da bis etwa 2 Tage vor Beginn der Symptome eine Infektiosität vorliegen kann.

Bei Vorliegen eines negativen SARSCoV-2-Abstrichs ist zu berücksichtigen, dass selbst eine PCR keine $100 \%$ Sicherheit darstellt und das Ergebnis immer nur eine Momentaufnahme darstellt. Nach einer Abstrichentnahme ist zudem mit einer Latenz zwischen dem Abstrich und der Übermittlung des Ergebnisses zu rechnen.

Diese Leitlinie erscheint auch in der Zeitschrift Klinische Monatsblätter für Augenheilkunde, Georg Thieme Verlag, Stuttgart.

\author{
Deutsche Ophthalmologische Gesellschaft (DOG) ${ }^{1} \cdot$ Berufsverband der \\ Augenärzte Deutschlands e. V. (BVA) ${ }^{2}$ \\ ' Deutsche Ophthalmologische Gesellschaft, München, Deutschland \\ ${ }^{2}$ Berufsverband der Augenärzte Deutschlands e.V., Düsseldorf, Deutschland
}

\title{
Empfehlungen von DOG und BVA zur Perimetrie während der SARS-CoV-2-Pandemie
}

\author{
Stand: 30. November 2020
}

Deswegen sollen, um Patienten und Personal untereinander vor einer SARSCoV-2-Infektion zu schützen, bei allen Patienten und dem Personal alle bekannten infektionspräventiven Maßnahmen (AHA-L-Regeln) bestmöglich umgesetzt werden und auf die spezifische Situation adaptiert werden.

Zur Verminderung des Infektionsrisikos sollen Begleitpersonen in Augenarztpraxen und Augenklinikambulanzen nur in dringend erforderlichen Fällen zugelassen werden, wobei dies speziell bei der Perimetrie nur in sehr seltenen Einzelfällen notwendig sein dürfte.

In allen Räumen der Einrichtungen im Bereich der Augenheilkunde, in denen sich Patienten aufhalten, sollen alle Patienten einen Mund-Nase-Schutz und das Personal zumindest einen medizinischen Mund-Nase-Schutz tragen.

Auf einen guten Sitz des Mund-NaseSchutzes soll geachtet werden, damit der Luftstrom der Ausatemluft in die Perimeterkugel möglichst gering ist. Insbesondere die Dichtigkeit des Maskensitzes nach oben soll vor der Untersuchung geprüft werden, auch um ein Beschlagen der Korrekturgläser zu vermeiden. Dabei kann ggf. ein Pflaster am Oberrand des Mund-Nase-Schutzes verwendet werden.

Gespräche sollen im Perimeterraum aufdas Notwendigste beschränkt werden.

Wiederverwendbare Abdeckkappen für das nicht zu untersuchende Auge sollen nicht verwendet werden, sondern stattdessen z.B. Einmal-Okklusionspflaster.

Nach jeder Untersuchung soll der Raum gelüftet werden. Dabei soll bei Räumen ohne Fenster je nach RaumgröBe mindestens 5-10 min mit weit offener Tür, bei kleinen Räumen mit weit offenem Fenster und Tür ca. 3 min gelüftet werden. Sofern eine raumlufttechnische Anlage (RLT-Anlage) mit $100 \%$ Frischluft bzw. Umluft mit HEPA-Filtration oder F7- und F9-Filtern vorhanden ist ${ }^{1}$, kann auf das Lüften verzichtet werden.

Druckknopf und Handauflagestellen sowie Stirnstütze und, falls kein Wechsel einer Papierauflage erfolgt, Kinnstütze sollen mit alkoholischem Wischtuch mit einem VAH-gelisteten Präparat nach der Untersuchung abgewischt werden. Sofern dies aus Materialverträglichkeitsgründen nicht möglich ist, soll das vom Hersteller empfohlene Verfahren zur Desinfektion verwendet werden.

Falls mehr als ein Perimeter in einem Untersuchungszimmer steht, soll der Abstand so groß sein, dass ein Mindestabstand von $1,5 \mathrm{~m}$ zwischen den Personen und die empfohlenen Lüftungszeiten zwischen den Untersuchungen eingehalten werden.

Redaktionskomitee Prof. Dr. med. Bernd Bertram, Augenarztpraxis Aachen (federführend)

\footnotetext{
1 Eine fehlende RLT-Anlage rechtfertigt nicht
} den Kaufvon dezentralen Luftreinigern. 


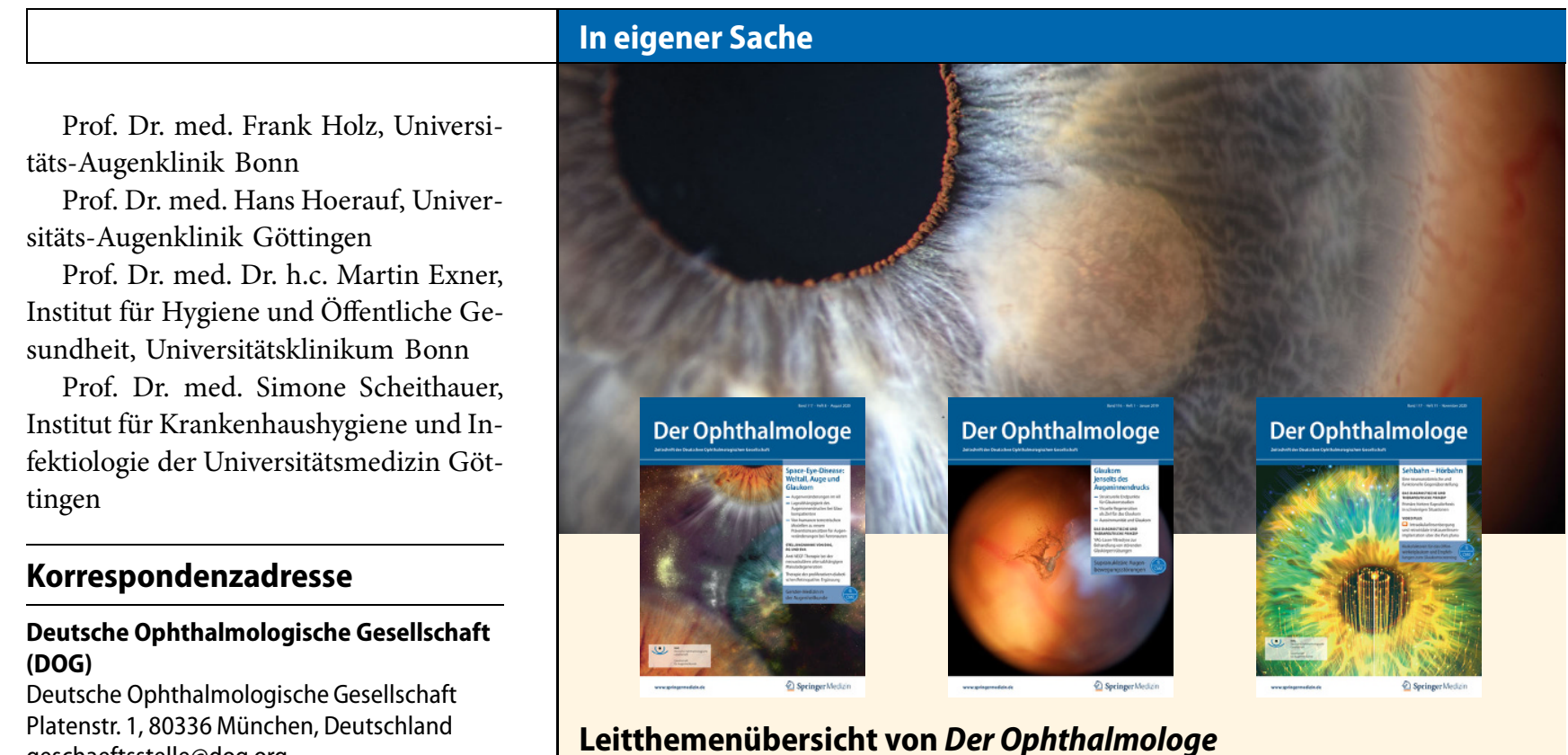

geschaeftsstelle@dog.org

Der Ophthalmologe bietet Ihnen jeden Monat umfassende und aktuelle Beiträge zu interessanten Themenschwerpunkten aus allen Bereichen der Augenheilkunde.

Rückblick - 2020

01/20 Originalien

02/20 Periokuläres Basalzellkarzinom

03/20 Maximalinvasive Vorder-

abschnittschirurgie im Kindesalter

04/20 Qualitätssicherung bei der IVOM

05/20 Der Femtosekundenlaser in der

Kataraktchirurgie

06/20 Personalisierte Medizin in der

Behandlung von Augentumoren

07/20 SARS-CoV-2-Infektion und Auge

08/20 Space-Eye-Disease:Weltall,

Auge und Glaukom

09/20 Retinologische Notfälle

10/20 Künstliche Intelligenz

11/20 Sehbahn - Hörbahn. Eine neuroanatomische und funktionelle Gegenüberstellung

12/20 Mikrochirurgische Operations-

techniken aus ophthalmopathologischer

Sicht

SpringerMedizin.de bietet Ihnen Zugang zu allen elektronisch verfügbaren Ausgaben Ihrer Zeitschrift - unabhängig davon, seit wann Sie die Zeitschrift abonniert haben.

\section{Vorschau - 2021}

01/21 Die Proliferative Vitreoretinopathie 02/21 Neuronale Ceroid-Lipofuszinosen 03/21 Die postoperative Endophthalmitis 04/21 OCT-Biomarker bei traktiven Makulopathien

05/21 Neue Glaukommedikamente 06/21 Pseudotumor orbitae 07/21 Originalien 08/21 Neuentwicklungen bei Hochrisikokeratoplastik

09/21 Neue digitale Möglichkeiten für die Augenheilkunde

10/21 Interdisziplinäre Versorgung von Orbitalen Tumoren

11/21 Notfalldiagnose Zentralarterienverschluss

12/21 Smartphone basierte Fundusfotografie

(Änderungen vorbehalten)

Alle Inhalte der Zeitschrift finden Sie unter www.springermedizin.de/ der-ophthalmologe 